\title{
Multibacterial Sepsis in an Alcohol Abuser with Hepatic Cirrhosis
}

\author{
Yoshihiro Matsukawa, Noboru Kitamura, Motohide KaneKo, Daijirou YoshiokA, \\ Takaaki MiKI, Susumu NishinARITA, Takashi Horie, Naoto HosoKAWA*, \\ Yoh IWASAKI*, Kazunari KUMASAKA* and Kinya KAWANO*
}

\begin{abstract}
An alcohol abuser with hepatitis $\mathrm{C}$ developed multibacterial sepsis. His mean $100 \%$ alcohol intake reached $400 \mathrm{ml} /$ day. In January 2001, he suddenly experienced fever $\left(39^{\circ} \mathrm{C}\right)$ with no other symptoms. One week later, he was admitted to our hospital and was subsequently diagnosed with sepsis associated with four species of bacteria (Streptococcus constellatus, Fusobacterium mortiferum, Bacteroides thetaiotaomicron, and non-spore-forming anaerobic gram-positive bacillus). A drip infusion of imipenem/cilastatin was administrated, resulting in a successful therapeutic outcome. No underlying disorder was found except for gastric ulcers and hepatic cirrhosis. Damaged gastric mucosa was assumed to be the possible cause and route for the bacterial invasion.

(Internal Medicine 42: 208-210, 2003)
\end{abstract}

Key words: alcohol abuser, Bacteroides thetaiotaomicron, Fusobacterium mortiferum, gastric ulcer, hepatic cirrhosis, multibacterial sepsis, Streptococcus constellatus

\section{Introduction}

Immunodeficient patients such as those with AIDS, cancer, or rheumatic diseases are likely to develop opportunistic or superimposed infection, but cases of multibacterial sepsis have rarely been reported (1). We encountered a patient with hypertension and hepatic cirrhosis who developed multibacterial sepsis involving four distinct bacterial species.

\section{Case Report}

On January 7, 2001, a 68-year-old Japanese man, under care at our outpatient clinic for chronic hepatitis $\mathrm{C}$ and hypertension (4 mg/day candesartan), suddenly had a fever (39 ${ }^{\circ} \mathrm{C}$ ) without other symptoms. He did not visit our clinic during this time. After one week of self-treatment with nonsteroidal anti-inflammatory drugs (NSAIDs), the patient visited a physician near his home. Although the physician prescribed an antibiotic and continued use of an NSAID, the patient showed no improvement. He finally came to our outpatient clinic on February 14, exhibiting lethargy and severe fatigue, with a temperature of $39.2^{\circ} \mathrm{C}$. Physical examination was otherwise unremarkable, and initial laboratory data disclosed a severe inflammatory process: C-reactive protein (CRP) $(23.8 \mathrm{mg} / \mathrm{dl}), \mathrm{WBC}(12,000 / \mu \mathrm{l})$, and erythrocyte sediment rate $(80 \mathrm{~mm} / \mathrm{h})$. Hepatorenal functions were abnormal, as shown by elevated serum levels of total bilirubin (2.11 $\mathrm{mg} / \mathrm{dl}$ ), asparate aminotransferase/alanine aminotransferase (AST/ALT) $(77 / 62 \mathrm{U} / \mathrm{l})$, urea nitrogen $(\mathrm{UN})(40.4 \mathrm{mg} / \mathrm{dl})$, and creatinine $(1.22 \mathrm{mg} / \mathrm{dl})$. Cholinesterase was within the patient's usual range (45 U/l: normal $200-450 \mathrm{U} / l$ ). He was admitted to our hospital for diagnostic workup and treatment of the pyrexia. Extensive tests including Ga scintigraphy failed to detect the etiology of the fever. Abdominal CT showed a hypertrophic left hepatic lobe with irregular margins. Ascites and cholelithiasis were not demonstrated. On the fourth hospital day, growth of four bacterial species (a gram-positive coccus, an anaerobic gram-positive bacillus, and two anaerobic gram-negative bacilli) was verified in the blood sample drawn on admission, and an intravenous infusion of imipenem/cilastatin $2.0 \mathrm{~g} /$ day was subsequently initiated. On February 20, a final report on the blood culture confirmed colonies of four bacteria: Streptococcus constellatus, Fusobacterium mortiferum, Bacteroides thetaiotaomicron, and non-spore-forming anaerobic gram-positive

From Department of Internal Medicine I and *Department of Laboratory Medicine, Nihon University School of Medicine, Tokyo

Received for publication July 1, 2002; Accepted for publication November 8, 2002

Reprint requests should be addressed to Dr. Yoshihiro Matsukawa, Department of Internal Medicine I, Nihon University School of Medicine, 30-1 Oyaguchi-Kamimachi, Itabashi-ku, Tokyo 173-8610 
bacillus. The fever subsided on February 21 following seven days of the antibiotic therapy by which time the hepatorenal functions returned to pre-onset levels (AST/ALT, 37/29 U/l; total bilirubin, $1.95 \mathrm{mg} / \mathrm{dl}$; UN, $9.4 \mathrm{mg} / \mathrm{dl}$; creatinine, 0.57 $\mathrm{mg} / \mathrm{dl}$; and cholinesterase, $54 \mathrm{U} / l$ ). During the patient's hospitalization, iron deficiency anemia rapidly developed: hemoglobin levels fell $3.2 \mathrm{~g} / \mathrm{dl}$ in four days. On February 22, gastroduodenoscopic examination detected multiple open ulcers in the region of the stomach body and angle. The patient was discharged on March 6, 2001.

During patient's hospital stay, we checked for dental, otolaryngeal, and anorectal lesions. No further significant abnormalities were detected. We also confirmed the patient had no immunologic abnormalities: autoantibodies, complements, serum immunoglobulins, lymphocyte proliferation to mitogens (phytohemagglutinin, poke weed mitogen, or concanavalin-A), and the numbers of CD3-, CD4-, CD8-, and CD19-positive cells were within normal ranges. Serologic tests were negative for HIV, EB virus, hepatitis A and $\mathrm{B}$ viruses, and cytomegalovirus. Thus, the patient was considered to have no underlying disease except for that of hepatic cirrhosis. During the hospitalization period, we reviewed and repeated the clinical history and discovered the patient was a prolonged ethanol abuser. His drinking began when he was in his 20s, and has continued to the present, and it was his habit at the time of hospitalization. He regularly consumes one-half bottle of whiskey plus an additional 450 $\mathrm{ml}$ of Japanese alcohol (30 volume \%) per day. Thus his mean daily consumption of $100 \%$ alcohol approaches nearly $400 \mathrm{ml}$.

\section{Discussion}

Multibacterial sepsis is uncommon and only observed in immunocompromised patients with such disease entities as cancer, rheumatic diseases, or AIDS. Such sepsis is intimately related to treatment or exacerbation of underlying diseases. In the present case, we searched extensively for a possible underlying disease such as cancer, rheumatic diseases or viral infection as well as lesions in the dental, otolaryngeal, or anorectal organs. Despite extensive testing, no specific findings were confirmed except for chronic hepatitis $\mathrm{C}$ with cirrhosis (hypertrophy of the left lobe, irregular surface, and low serum levels of choline esterase).

When making a diagnosis of sepsis, it is important for one to verify the route of invasion of the pathogens, however we could not make this determination with our patient. Since the usual routes of bacterial invasion were ruled out in this patient, we then theorized that the multiple bleeding ulcers in the stomach body and angle were the most likely site of invasion. Furthermore, the four bacteria detected usually colonize the mucosal surface of the alimentary canal including the stomach $(2,3)$. Although we cannot verify the initial vector or timing of the infection, i.e., whether sepsis preceded ulcer formation or ulcer formation preceded sepsis, we do know these pathogens can invade the circulation via ulcer craters.
In fact, some investigators have reported such a gastric ulcerinduced sepsis $(4,5)$.

The patient's daily alcohol consumption (a mean $100 \%$ alcohol intake of nearly $400 \mathrm{ml} /$ day) may have been a contributing factor in the infection. Chronic alcohol ingestion is known to suppress neutrophil functions, myeloid colony formation, cell-mediated immune functions, and NK cell activity (6-9), and in addition, may lead to folic acid deficiency that can deplete myeloid precursors in the bone marrow. Epidemiologic investigations of alcohol abusers, particularly those with leukopenia (10) or hepatic cirrhosis (11) indicate susceptibility to many infectious diseases. The mortality and morbidity rate for pulmonary infection, sepsis, peritonitis, and meningitis are high among ethanol abusers (10). Furthermore, episodes of bacteremia and spontaneous bacterial peritonitis (almost all patients have ascites) are reported to be common among alcoholics with hepatic cirrhosis (12). Aerobic gram-negative bacilli and pneumococcus are the two major pathogens found in this population. Since the present patient had demonstrated the abdominal CT findings and low serum levels of cholinesterase suggesting hepatic cirrhosis, and the four pathogens detected are common inhabitants of the intestine including the stomach, it would seem our patient's clinical course appears to parallel that of the classic immunocompromised chronic alcoholic with cirrhosis (11).

In conclusion, we describe a case in which an ethanol abuser with hepatic cirrhosis developed multibacterial sepsis (both gram-negative and gram-positive anaerobic bacilli) most probably due to suppressed immune function associated with chronic alcohol ingestion and hepatic cirrhosis. We contend that gastric ulcer craters may be the primary invasion route of these anaerobic bacteria, all of which have been known to colonize the gastric mucosal surface.

\section{References}

1) Gimenez $S$, Vecina $T$, Cachot $T$, et al. Bacteremia of cutaneous origin. An Med Interna 7: 402-405, 1990 (In Spanish, Abstract in English).

2) Murray PR, Rosenthal KS, Kobayashi GS, Pfaller MA. Anaerobic gram- positive cocci and nonspore-forming bacilli. in: Medical microbiology 3rd ed. Murray PR, Rosenthal KS, Kobayashi GS, Pfaller MA Eds. Mosby-Year Book Inc., St. Louis, Missouri, 1998: 291-295.

3) Murray PR, Rosenthal KS, Kobayashi GS, Pfaller MA. Anaerobic gram-negative bacilli. in: Medical Microbiology 3rd ed. Murray PR, Rosenthal KS, Kobayashi GS, Pfaller MA Eds. Mosby-Year Book Inc., St. Louis, Missouri, 1998: 308-312.

4) Skillman JJ, Bushnell LS, Goldman H, Silen W. Respiratory failure, hypotension, sepsis, and jaundice. A clinical syndrome associated with lethal hemorrhage from acute stress ulceration of the stomach. Am J Surg 117: 523-530, 1969.

5) Koehler M, Kasner J. Septicemia complicated by acute stomach ulcer in a 4-month-old infant. Pediatr Pol 58: 101-102, 1983 (In Polish).

6) Gluckman SJ, Dvorak VC, MacGregor RR. Host defenses during prolonged alcohol consumption in a controlled environment. Arch Intern Med 137: 1539-1543, 1977.

7) MacGregor RR, Gluckman SJ, Senior JR. Granulocyte function and levels of immunoglobulins and complement in patients admitted for withdrawal from alcohol. J Infect Dis 138: 747-755, 1978.

8) Glassman AB, Bennett CE, Rendall CL. Effects of ethyl alcohol on human peripheral lymphocytes. Arch Pathol Lab Med 109: 540-542, 
MATSUKAWA et al

1985.

9) MacGregor RR, Louria DB. Alcohol and infection. Cur Clin Top Infect Dis 17: 291-315, 1997.

10) Perlino CA, Rimland D. Alcoholism, leukopenia, and pneumococcal sepsis. Am Rev Respir Dis 132: 757-760, 1985.
11) Whipple RI, Harris JF. E. coli septicemia in Laennec's cirrhosis of the liver. Ann Intern Med 33: 462-466, 1950.

12) Adams HG, Jordan C. Infections in the alcoholic. Med Clin North Am 68: 179-200, 1984. 